\title{
Rates and Risk Factors in Macrosomic Newborns among Non-Diabetic Parturients at Tiznit City, Morocco: A Case-Control Study
}

\author{
Amal Korrida ${ }^{1,2}$ \\ ${ }^{1}$ Higher Institute of Nursing Professions and Health Techniques, ISPITS of Agadir-Annex of Tiznit, Ministry of Health, \\ Kingdom of Morocco \\ ${ }^{2}$ Cellular Biology and Molecular Genetics Laboratory, Faculty of Sciences, Ibn Zohr University, Kingdom of Morocco \\ Email: amalkorrida11@aol.com
}

How to cite this paper: Korrida, A. (2017) Rates and Risk Factors in Macrosomic Newborns among Non-Diabetic Parturients at Tiznit City, Morocco: A Case-Control Study. Open Access Library Journal, 4: e4225.

https://doi.org/10.4236/oalib.1104225

Received: November 30, 2017

Accepted: December 18, 2017

Published: December 21, 2017

Copyright $\odot 2017$ by author and Open Access Library Inc.

This work is licensed under the Creative Commons Attribution International License (CC BY 4.0).

http://creativecommons.org/licenses/by/4.0/

\begin{abstract}
Background: The present study was elaborated to assess the prevalence of high birth weight and its related risk factors for macrosomic infants among women in Southern Morocco. Methods: A case-control study was conducted on term singleton live-births, with no morbidity or malformation, of a sample of $(n=78)$ nulliparous and multiparous non-diabetic women delivering at Hassan I Provincial Hospital. Cases included neonates $\geq 4000 \mathrm{~g}$, whereas controls comprised infants with birth weight between 2500 and 3999 g. Personal information was collected from pregnant women using a structured questionnaire, and through a review of their medical records. Associations between exposure and dependent variable (macrosomia) were calculated using linear and logistic regressions. Results: Macrosomia prevalence was 35.89\%. Mean birth weight in cases was $4310.71 \pm 246.96 \mathrm{~g}$, and in controls $3076.00 \pm$ 533.97 g. Maternal lifestyle behaviors, as well as sociodemographic factors were not associated with macrosomia, except for maternal age over 40 years (OR: 4.27, 95\% CI: 0.98 - 18.68). Logistic regression model analysis indicated that macrosomia was strongly associated with hormone therapy (adjusted OR: 18.83, 95\% CI: 1.54 - 214.51), followed by obesity/overweight history (adjusted OR: 7.94, 95\% CI: 1.52 - 41.41), and pre-pregnancy BMI $\geq 25 \mathrm{Kg} / \mathrm{m}^{2}$ for pooled overweight and obesity factor (adjusted OR: 5.24, 95\% CI: 1.54 17.82). Conclusion: Pre-pregnancy BMI $>25 \mathrm{~kg} / \mathrm{m}^{2}$, pre-existing overweight/ obesity, and hormone therapy should be considered as independent risk factors for fetal macrosomia and require more attention from health professionals.
\end{abstract}

\section{Subject Areas}

Epidemiology, Women's Health, Nutrition 


\section{Keywords}

Macrosomia, Nutritional Status, Risk Factors, Hormone Therapy, Pre-Pregnancy BMI, Caesarean Section, Obesity

\section{Introduction}

Macrosomia is an obstetric term used to indicate excessive birth weights or intrauterine growth, generally of more than $4000 \mathrm{~g}$, which corresponds to the $90^{\text {th }}$ centile at 40 weeks of gestation [1]. This disease can potentially lead to significant health outcomes for both the mother and the infant. Mothers of macrosomic newborns are more likely to be at increased risk of prolonged labor, perineal trauma, caesarean section, post-partum haemorrhage and anal sphincter ruptures [2] [3], whereas large newborns may face several short-term effects. These include birth asphyxia and injury, shoulder dystocia, and increased risk of neonatal mortality and morbidity. Long-term complications comprise high risks for diabetes mellitus, hypertension, cardiovascular diseases, cancer, and obesity [4]. Several epidemiologic studies have focused on this condition, and have identified a number of risk factors for macrosomic births. These encompass preexisting maternal diabetes, maternal age over 40 years, multi-parity, high pre-gravid body mass index (BMI $\left.\geq 25 \mathrm{~kg} / \mathrm{m}^{2}\right)$, maternal height $(\geq 165 \mathrm{~cm})$, excessive gestational weight gain (GWG), male sex, prolonged gestation $(>41$ weeks), placental factors, parental non-smoking status, preexisting gestational diabetes, maternal obesity/overweight, and lifestyle behaviors [5]. Although macrosomia's risk factors have been well studied, the reasons behind it are still complex and unclear. Approximately $60 \%$ of macrosomic infants are born to mothers without identifiable risk factors [6], also $80 \%$ of the cases are not associated to maternal diabetes mellitus [7]. Currently, the rates of macrosomic babies have been increasing in both developed and developing countries. For instance, macrosomia prevalence was assessed to $21.2 \%$ among north Norwegian women [8], 10.5\% in Ghana [9], between $14 \%$ and $18 \%$ at the USA [10], $8.63 \%$ in Belgium [11], and 34.3\% in Canada [12]. In Morocco, during the last two decades, macrosomia prevalence ranged from $5.64 \%$ to $14.37 \%$ [13] [14], where the majority of the studies were conducted in big metropolitan cities such as: Casablanca, Rabat, Marrakech and Fez. High birth weight represents real challenges for physicians, since attempts at perinatal diagnosis of macrosomia have been proven to be difficult and prone to significant errors [15]. Indeed, the antenatal diagnosis of fetal macrosomia remains problematic despite continuing advances in obstetric ultrasound technique [16].

Thus, the present study aims to determine the prevalence of macrosomia in healthy and non-diabetic mothers, and to predict this disease based on its associated risk factors. This will be the first case-control study to be carried out in Souss-Massa Region, among pregnant women living at Tiznit Province. 


\section{Materials \& Methods}

\subsection{Study Setting and Design}

This study took place at the maternity of the Centre Hospitalier Provincial (CHP) Hassan I in Tiznit city, Morocco, from November the $21^{\text {st }}$ to December the $30^{\text {th }} 2016$. Initially, a total of 93 pregnant women were recruited. Exclusion criteria were then, diabetic women $(n=11)$ and twin or multiple pregnancies ( $n$ $=4$ ). A sample size of 61 was estimated using StatCalc in Epi Info ${ }^{\text {tw }}$ software, and considering the most recent prevalence of macrosomia assessed in Morocco (i.e.: $\sim 6 \%$ ) [13], a confidence level of $90 \%$, and a margin of error of $5 \%$. However, the study sample included a group of healthy and non-diabetic mothers $(n=78)$ with singleton-live and healthy neonates, born by vaginal delivery or caesarean section, urban and rural pregnant women were either nulliparous or multiparous, with 37 to 42 weeks of gestational age (i.e.: full-term). Data was collected by two trained undergraduate midwife students of the Institut Supérieur des Professions Infirmières et Techniques de Santé (ISPITS) of Tiznit, and supervised continuously by the principal researcher of the study, in addition, to the nurses or healthcare staff of the CHP maternity. Neonatal information and outcomes were prospectively tracked at the hospital maternity, whereas general maternal medical records were extracted retrospectively from the hospital pregnancy files and health notebooks. Further data were collected during one antenatal face-to-face interview through a structured questionnaire pertaining to personal participant characteristics, mainly (i) sociodemographic variables: maternal age, education status, residence, ethnicity and profession, (ii) maternal medical and reproductive variables: height, pre-pregnancy body mass index (BMI), self-reported pre-pregnancy weight (that was compared to the first trimester weight), gestational weight gain (GWG), parity, self-reported histories of diabetes mellitus, hypertension, macrosomia, as well as overweight and obesity, and hormone therapy, and (iii) maternal lifestyle variables: nutrition and physical activity. Pre-pregnancy BMI was calculated using the first trimester pre-pregnancy weight and measured maternal height as $\left(\mathrm{kg} / \mathrm{m}^{2}\right)$, and categorized according to the World Health Organization (WHO) criteria into underweight $\left(\mathrm{BMI}<18.5 \mathrm{~kg} / \mathrm{m}^{2}\right)$, average $\left(18.5<\mathrm{BMI}<24.9 \mathrm{~kg} / \mathrm{m}^{2}\right)$, overweight $(25<\mathrm{BMI}<$ $\left.29.9 \mathrm{~kg} / \mathrm{m}^{2}\right)$, obese $\left(B M I \geq 30 \mathrm{~kg} / \mathrm{m}^{2}\right)$, in addition to pooled overweight/obesity (BMI $\geq 25 \mathrm{~kg} / \mathrm{m}^{2}$ ) group [17]. GWG was assessed by subtracting pre-pregnancy weight at the first trimester as mentioned on the maternity medical record, from the maternal weight at the last antenatal visit, just before the delivery. Furthermore, GWG was classified according to the Institute of Medicine (IOM) 2009 guidelines [18], and based on pre-pregnancy BMI as: 12.5 - $18 \mathrm{~kg}$ for underweight, 11.5 - $16 \mathrm{~kg}$ for normal, $7-11.5 \mathrm{~kg}$ for overweight, and 5 - $9 \mathrm{~kg}$ for obese statuses. Women were then classified into above, within, and below the Institute of Medicine (IOM) recommendations. In other terms, excessive GWG for example, was defined as gaining body weight superior to $18 \mathrm{~kg}$ for underweight, superior to $16 \mathrm{~kg}$ for average weight, superior to $11.5 \mathrm{~kg}$ for overweight, and su- 
perior to $9 \mathrm{~kg}$ for obese pregnant women. Gestational age was calculated by the date of the last menstrual period, and macrosomia was defined as birth weight equal or greater than $4000 \mathrm{~g}$ [19].

\subsection{Ethical Considerations}

The present investigation was carried out in compliance with the Helsinki declaration that adopted its ethical principles for medical research involving human subjects. This observational research respected also the decision of Moroccan Ministry of Health on non-interventional biomedical research, and therefore, was given the approval from the Provincial Health Authority, besides written permissions from Tiznit ISPITS and Hassan I CHP administrations. The study objectives were verbally explained to the patients before their participation, and a written informed consent was obtained from each pregnant mother.

\subsection{Statistical Analysis}

Descriptive statistics were presented in percentages and frequencies for qualitative data, and in arithmetic mean \pm standard deviation for quantitative data. The independent 2-samples t-test and Pearson's Chi-squared test were used for statistical comparisons of continuous and categorical variables between cases and controls, respectively. A p-value less than $5 \%$ was considered statistically significant for all analysis. The dependent and unique variable was the occurrence of macrosomia as a dichotomized outcome. The independent variables were: maternal age, education level, residence, ethnicity, profession, maternal height, pre-gravid BMI, GWG below, within and above the IOM recommendations, parity, mode of delivery, histories of diabetes, hypertension, macrosomia and obesity/overweight, gestational age and maternal lifestyle characteristics (i.e.: physical activity, consumption of fish/seafood, fruits, vegetables, fats and charcuteries, lean meat, soda, tea/coffee, alcohol, cigarettes, and exposition to passive smoking during pregnancy). Linear and logistic regression analyses were implemented to assess odds ratios (ORs) and their 95\% confidence intervals (95\% $\mathrm{CI}$ ). In multivariate analyses, logistic regression models were performed on variables that were statistically significant in the univariate analyses (or in correlation tests). Thereby, adjustments were applied for the eventual confounding factors: maternal age $\geq 40$ years, gestational age $>40$ weeks, obesity/overweight history, macrosomia history, and pre-pregnancy BMI $\geq 25 \mathrm{~kg} / \mathrm{m}^{2}$ for pooled overweight and obesity statuses. The statistical analyses were performed using Statistical Package for Social Science (IBM ${ }^{\bullet}$ SPSS $^{\circledR}$ statistics, version 22, Chicago IL, USA) and Epi Info ${ }^{\text {tm }}$ software, version 7.2.0.3 (Center for Disease Control \& Prevention CDC, USA, 2017).

\section{Results}

Maternal and neonates general characteristics are summarized in Table 1. Concerning non-diabetic pregnant women, a total of 28 cases were included in the 
Table 1. Mean, standard deviation and frequencies for selected characteristics among overall pregnant women $(n=89)$ and non-diabetic women $(n=78)$.

\begin{tabular}{|c|c|c|c|c|c|c|}
\hline & \multicolumn{3}{|c|}{ Overall } & \multicolumn{3}{|c|}{ Non-diabetic } \\
\hline & $\%(\mathrm{n} /$ Total $)$ & Mean & S.d & $\%(\mathrm{n} /$ Total $)$ & Mean & S.d \\
\hline \multicolumn{7}{|l|}{ Maternal characteristics } \\
\hline Age (years) & & 27.66 & 6.56 & & 27.75 & 6.76 \\
\hline$<20$ & $3.37(3 / 89)$ & & & $3.85(3 / 78)$ & & \\
\hline$[20-30]$ & $56.18(50 / 89)$ & & & $53.85(42 / 78)$ & & \\
\hline$[30-40]$ & $30.33(27 / 89)$ & & & $30.77(24 / 78)$ & & \\
\hline$>40$ & $10.11(9 / 89)$ & & & $11.54(9 / 78)$ & & \\
\hline \multicolumn{7}{|l|}{ Education (years) } \\
\hline None & $12.35(11 / 89)$ & & & $12.82(10 / 78)$ & & \\
\hline$<5$ & $24.71(22 / 89)$ & & & $25.64(20 / 78)$ & & \\
\hline$[5-9]$ & $35.95(32 / 89)$ & & & $34.62(27 / 78)$ & & \\
\hline$[9-12]$ & $14.60(13 / 89)$ & & & $14.10(11 / 78)$ & & \\
\hline$>12$ & $12.35(11 / 89)$ & & & $12.82(10 / 78)$ & & \\
\hline \multicolumn{7}{|l|}{ Residence } \\
\hline Urban & $67.41(60 / 89)$ & & & $65.38(51 / 78)$ & & \\
\hline Rural & $32.59(29 / 89)$ & & & $34.62(27 / 78)$ & & \\
\hline \multicolumn{7}{|l|}{ Ethnicity } \\
\hline Arab & $41.57(37 / 89)$ & & & $39.74(31 / 78)$ & & \\
\hline Amazigh & $58.43(52 / 89)$ & & & $60.26(47 / 78)$ & & \\
\hline \multicolumn{7}{|l|}{ Profession } \\
\hline Yes & $14.60(13 / 89)$ & & & $12.82(10 / 78)$ & & \\
\hline No & $85.40(76 / 89)$ & & & $87.18(68 / 78)$ & & \\
\hline Height (m) & & 1.59 & 0.05 & & 1.59 & 0.06 \\
\hline$[1.4-1.5]$ & $1.12(1 / 89)$ & & & $1.28(1 / 78)$ & & \\
\hline$[1.5-1.6]$ & $46.06(41 / 89)$ & & & $43.59(34 / 78)$ & & \\
\hline$[1.6-1.7]$ & $56.17(45 / 89)$ & & & $52.56(41 / 78)$ & & \\
\hline$>1.7$ & $2.24(2 / 89)$ & & & $2.56(2 / 78)$ & & \\
\hline Pre-pregnancy BMI $\left(\mathrm{kg} / \mathrm{m}^{2}\right)$ & & 25.50 & 3.78 & & 25.24 & 3.82 \\
\hline Underweight $(<18.5)$ & $1.12(1 / 89)$ & & & $1.28(1 / 78)$ & & \\
\hline Normal (18.5 - 24.9) & $50.56(45 / 89)$ & & & $52.56(41 / 78)$ & & \\
\hline Overweight (25 - 29.9) & $37.07(33 / 89)$ & & & $35.39(28 / 78)$ & & \\
\hline Obese $(>30)$ & $11.23(10 / 89)$ & & & $10.25(8 / 78)$ & & \\
\hline Overweight and obesity (>25) & $48.31(43 / 89)$ & & & $46.15 \quad(36 / 78)$ & & \\
\hline Overall gestational weight gain $(\mathrm{kg})$ & & 8.09 & 2.32 & & 7.80 & 2.12 \\
\hline GWG above IOM & $7.86(7 / 89)$ & & & $7.69(6 / 78)$ & & \\
\hline GWG within IOM & $33.70(30 / 89)$ & & & $42.30(33 / 78)$ & & \\
\hline GWG below IOM & $58.42(52 / 89)$ & & & $50.00(39 / 78)$ & & \\
\hline
\end{tabular}




\begin{tabular}{|c|c|c|c|c|c|c|}
\hline & \multicolumn{3}{|c|}{ Overall } & \multicolumn{3}{|c|}{ Non-diabetic } \\
\hline & $\%(\mathrm{n} / \mathrm{Total})$ & Mean & S.d & $\%(n / T o t a l)$ & Mean & S.d \\
\hline \multicolumn{7}{|l|}{ Maternal characteristics } \\
\hline \multicolumn{7}{|l|}{ Parity } \\
\hline Primipare & $36.00(32 / 89)$ & & & $34.62(27 / 78)$ & & \\
\hline Multipare & $64.00(57 / 89)$ & & & $65.38(51 / 78)$ & & \\
\hline \multicolumn{7}{|l|}{ Mode of delivery } \\
\hline Vaginal delivery & $67.40(60 / 89)$ & & & $67.95(53 / 78)$ & & \\
\hline Caesarian section & $32.60(29 / 89)$ & & & $32.05(25 / 78)$ & & \\
\hline History of preexisting diabetes mellitus & $12.35(11 / 89)$ & & & **** & & \\
\hline History of preexisting hypertension & $3.37(3 / 89)$ & & & $2.56(2 / 78)$ & & \\
\hline History of preexisting macrosomia & $12.35(11 / 89)$ & & & $11.54(9 / 78)$ & & \\
\hline History of preexisting overweight and/or obesity & $19.10(17 / 89)$ & & & $17.95(14 / 78)$ & & \\
\hline \multicolumn{7}{|l|}{ Hormonal treatment } \\
\hline Yes & $7.90(7 / 89)$ & & & $8.97(7 / 78)$ & & \\
\hline No & $92.10(82 / 89)$ & & & $91.03(71 / 78)$ & & \\
\hline \multicolumn{7}{|l|}{ Infant characteristics } \\
\hline Birthweight (g) & & 3608.98 & 745.69 & & 3519.23 & 747.12 \\
\hline Birthweight < $4000 \mathrm{~g}$ (Normal) & $58.42(52 / 89)$ & & & $64.10(50 / 78)$ & & \\
\hline Birthweight $\geq 4000 \mathrm{~g}$ (Macrosomia) & $41.57(37 / 89)$ & & & $35.89(28 / 78)$ & & \\
\hline Gestational age (weeks) & & 39.10 & 1.72 & & 39.03 & 1.81 \\
\hline$<38$ & $11.23(10 / 89)$ & & & $12.82(10 / 78)$ & & \\
\hline$[38-40]$ & $74.15(66 / 89)$ & & & $71.79(56 / 78)$ & & \\
\hline$>40$ & $14.60(13 / 89)$ & & & $15.38(12 / 78)$ & & \\
\hline
\end{tabular}

Abbreviations: n, Number; S.d, Standard deviation; BMI, Body mass index.

study, which correspond to a prevalence of macrosomia of $35.89 \%$. Average age at conception was estimated to $27.75 \pm 6.76$ years, maternal height to $1.59 \pm 0.06$ meter, and gestational age at delivery above 40 weeks represented $15.38 \%$. More than $60 \%$ of pregnant women had a pre-pregnancy BMI $\geq 25 \mathrm{~kg} / \mathrm{m}^{2}$ and were multiparous. The mode of delivery by means of caesarean section was noticed in $32.05 \%$ of the cases. The mean GWG among Tiznit pregnant women was estimated to $7.80 \pm 2.12 \mathrm{~kg}$ and $7.67 \%$ of them had excessive GWG. As for sociodemographic/economic characteristics, more than half of women were of Amazigh ethnicity, unemployed and urban residents. Table 2 showed that average birth weight in macrosomic infants was estimated to $4310.70 \pm 246.96 \mathrm{~g}$ versus $3076.00 \pm 533.97 \mathrm{~g}$ in controls. Furthermore, univariate analysis demonstrated that the likelihood of delivering a macrosomic infant was increased in pregnant women superior to 40 years of age (OR: 4.27, 95\% CI: 0.98 - 18.68). 
Table 2. Rates and unadjusted odds ratios (ORs) for infant macrosomia, by selected maternal and infant characteristics, among ( $n$ = 78) non-diabetic women.

\begin{tabular}{|c|c|c|c|c|c|}
\hline Maternal sociodemographic characteristics & Controls \% & Cases \% & OR & {$[95 \% \mathrm{CI}]$} & $P$-value \\
\hline \multicolumn{6}{|l|}{ Age (years) } \\
\hline$<20$ & $2.00(1 / 50)$ & $7.14(2 / 28)$ & 3.76 & $0.32-43.55$ & 0.25 \\
\hline$[20-30]$ & $52.00(26 / 50)$ & $57.14(16 / 28)$ & 1.23 & $0.48-3.12$ & 0.66 \\
\hline$[30-40]$ & $40.00(20 / 50)$ & $14.29(4 / 28)$ & 0.25 & $0.07-0.83$ & 0.01 \\
\hline$>40$ & $6.00(3 / 50)$ & $21.43(6 / 28)$ & 4.27 & $0.98-18.68$ & 0.04 \\
\hline \multicolumn{6}{|l|}{ Education (years) } \\
\hline None & $10.00(5 / 50)$ & $17.86(5 / 28)$ & 1.95 & $0.51-6.48$ & 0.35 \\
\hline$<5$ & $26.00(13 / 50)$ & $25.00(7 / 28)$ & 0.95 & $0.32-2.74$ & 0.92 \\
\hline$[5-9]$ & $32.00(16 / 50)$ & $39.29(11 / 28)$ & 1.37 & $0.52-3.60$ & 0.51 \\
\hline$[9-12]$ & $12.00(6 / 50)$ & $17.86(5 / 28)$ & 1.59 & $0.43-5.78$ & 0.47 \\
\hline$>12$ & $20.00(10 / 50)$ & $0.00(0 / 28)$ & UNDF & UNDF & 0.01 \\
\hline \multicolumn{6}{|l|}{ Residence } \\
\hline Urban & $66.00(33 / 50)$ & $64.29(18 / 28)$ & 0.92 & $0.35-2.44$ & 0.87 \\
\hline Rural & $34.00(17 / 50)$ & $35.71(10 / 28)$ & 1.07 & $0.40-2.84$ & 0.87 \\
\hline \multicolumn{6}{|l|}{ Ethnicity } \\
\hline Arab & $40.00(20 / 50)$ & $39.29(11 / 28)$ & 0.97 & $0.37-2.50$ & 0.95 \\
\hline Amazigh & $60.00(30 / 50)$ & $60.71(17 / 28)$ & 1.03 & $0.40-2.65$ & 0.95 \\
\hline \multicolumn{6}{|l|}{ Profession } \\
\hline No & $84.00(42 / 50)$ & $92.86(26 / 28)$ & 2.47 & $0.48-12.57$ & 0.26 \\
\hline Yes & $16.00(8 / 50)$ & $7.14(2 / 28)$ & 0.40 & $0.07-2.05$ & 0.26 \\
\hline \multicolumn{6}{|l|}{ Maternal health and reproductive characteristics } \\
\hline \multicolumn{6}{|l|}{ Height (m) } \\
\hline$[1.4-1.5]$ & $2.00(1 / 50)$ & $0.00(0 / 28)$ & 0.00 & UNDF & 0.45 \\
\hline$[1.5-1.6]$ & $38.00(19 / 50)$ & $53.57(15 / 28)$ & 1.88 & $0.73-4.80$ & 0.18 \\
\hline$[1.6-1.7]$ & $56.00(28 / 50)$ & $46.42(13 / 28)$ & 0.68 & $0.26-1.72$ & 0.41 \\
\hline$>1.7$ & $4.00(2 / 50)$ & $0.00(0 / 28)$ & 0.00 & UNDF & 0.28 \\
\hline \multicolumn{6}{|l|}{ Pre-pregnancy BMI $\left(\mathrm{kg} / \mathrm{m}^{2}\right)$} \\
\hline Underweight $(<18.5)$ & $2.00(1 / 50)$ & $0.00(0 / 28)$ & 0.00 & UNDF & 0.45 \\
\hline Normal (18.5 - 24.9) & $66.00(33 / 50)$ & $28.57(8 / 28)$ & 0.20 & $0.07-0.56$ & 0.00 \\
\hline Overweight (25 - 29.9) & $26.00(13 / 50)$ & $53.57(15 / 28)$ & 3.28 & $1.23-8.70$ & 0.01 \\
\hline Obese $(>30)$ & $6.00(3 / 50)$ & $17.85(5 / 28)$ & 3.40 & $0.74-15.50$ & 0.09 \\
\hline Overweight and obesity (>25) & $32.00(16 / 50)$ & $71.43(20 / 28)$ & 5.31 & $1.92-14.62$ & 0.00 \\
\hline \multicolumn{6}{|l|}{ Gestational weight gain $(\mathrm{kg})$} \\
\hline GWG below IOM & $60.00(30 / 50)$ & $32.14(9 / 28)$ & 0.31 & $0.11-0.83$ & 0.01 \\
\hline GWG within IOM & $40.00(20 / 50)$ & $46.43(13 / 28)$ & 1.30 & $0.51-3.30$ & 0.58 \\
\hline GWG above IOM & $0.00(0 / 50)$ & $21.43(6 / 28)$ & UNDF & UNDF & 0.00 \\
\hline \multicolumn{6}{|l|}{ Overweight/obesity pre pregnancy BMI } \\
\hline GWG below IOM & $18.75(3 / 16)$ & $20.00(4 / 20)$ & 1.08 & $0.20-5.73$ & 0.92 \\
\hline GWG within IOM & $81.25(13 / 16)$ & $55.00(11 / 20)$ & 0.28 & $0.06-1.30$ & 0.09 \\
\hline GWG above IOM & $0.00(0 / 16)$ & $25.00(5 / 20)$ & UNDF & UNDF & 0.03 \\
\hline
\end{tabular}




\section{Continued}

\begin{tabular}{|c|c|c|c|c|c|}
\hline Maternal health and reproductive characteristics & Controls \% & Cases \% & OR & {$[95 \% \mathrm{CI}]$} & $P$-value \\
\hline \multicolumn{6}{|l|}{ Gravidity } \\
\hline Primipare & $36.00(18 / 50)$ & $32.14(9 / 28)$ & 0.84 & $0.31-2.24$ & 0.73 \\
\hline Multipare & $64.00(32 / 50)$ & $67.86(19 / 28)$ & 1.18 & $0.45-3.16$ & 0.73 \\
\hline \multicolumn{6}{|l|}{ Mode of delivery } \\
\hline Vaginal delivery & $86.00(43 / 50)$ & $35.71(10 / 28)$ & 0.09 & $0.02-0.27$ & 0.00 \\
\hline Caesarian section & $14.00(7 / 50)$ & $64.29(18 / 28)$ & 11.05 & $3.63-33.60$ & 0.00 \\
\hline \multicolumn{6}{|l|}{ Self-reported history of hypertension } \\
\hline No & $100.00(50 / 50)$ & $92.85(26 / 28)$ & & 1 (Ref) & \\
\hline Yes & $0.00(0 / 50)$ & $7.14(2 / 28)$ & UNDF & UNDF & \\
\hline \multicolumn{6}{|l|}{ Self-reported history of macrosomia } \\
\hline No & $96.00(48 / 50)$ & $75(21 / 28)$ & & 1 (Ref) & \\
\hline Yes & $4.00(2 / 50)$ & $25(7 / 28)$ & 8.00 & $1.53-41.78$ & 0.00 \\
\hline \multicolumn{6}{|c|}{ Self-reported history of overweight and/or obesity } \\
\hline No & $94.00(47 / 50)$ & $60.71(17 / 28)$ & & 1 (Ref) & \\
\hline Yes & $6.00(3 / 50)$ & $39.29(11 / 28)$ & 10.13 & $2.52-40.77$ & 0.00 \\
\hline \multicolumn{6}{|l|}{ Hormonal treatment } \\
\hline No & $98.00(49 / 50)$ & $78.57(22 / 28)$ & & 1 (Ref) & \\
\hline Yes & $2.00(1 / 50)$ & $21.43(6 / 28)$ & 13.36 & $1.51-117.74$ & 0.00 \\
\hline \multicolumn{6}{|c|}{ Maternal nutrition and physical activity characteristics } \\
\hline \multicolumn{6}{|l|}{ Fish consumption during pregnancy } \\
\hline No & $4.00(2 / 50)$ & $3.57(1 / 28)$ & & 1.00 (Ref) & \\
\hline Yes & $96.00(48 / 50)$ & $96.43(27 / 28)$ & 1.12 & $0.09-12.98$ & 0.92 \\
\hline \multicolumn{6}{|l|}{ Lean meat (goat) consumption during pregnancy } \\
\hline No & $2.00(1 / 50)$ & $3.57(1 / 28)$ & & 1.00 (Ref) & \\
\hline Yes & $98.00(49 / 50)$ & $96.43(27 / 28)$ & 0.55 & $0.03-9.16$ & 0.67 \\
\hline \multicolumn{6}{|c|}{ Fats and charcuteries consumption during pregnancy } \\
\hline No & $20.00(10 / 50)$ & $25.00(7 / 28)$ & & 1.00 (Ref) & \\
\hline Yes & $80.00(40 / 50)$ & $75.00(21 / 28)$ & 0.75 & $0.24-2.25$ & 0.60 \\
\hline \multicolumn{6}{|l|}{ Soda consumption during pregnancy } \\
\hline No & $44.00(22 / 50)$ & $53.57(15 / 28)$ & & 1.00 (Ref) & \\
\hline Yes & $56.00(28 / 50)$ & $46.42(13 / 28)$ & 0.68 & $0.26-1.72$ & 0.41 \\
\hline \multicolumn{6}{|l|}{ Tea/coffee consumption during pregnancy } \\
\hline No & $40.00(20 / 50)$ & $60.71(17 / 28)$ & & 1.00 (Ref) & \\
\hline Yes & $60.00(30 / 50)$ & $39.29(11 / 28)$ & 0.43 & $0.16-1.11$ & 0.07 \\
\hline \multicolumn{6}{|l|}{ Vegetable consumption during pregnancy } \\
\hline No & $0.00(0 / 50)$ & $0.00(0 / 28)$ & & 1.00 (Ref) & \\
\hline Yes & $100.00(50 / 50)$ & $100.00(28 / 28)$ & 0.00 & UNDF & UNDF \\
\hline \multicolumn{6}{|l|}{ Fruit consumption during pregnancy } \\
\hline No & $0.00(0 / 50)$ & $0.00(0 / 28)$ & & 1.00 (Ref) & \\
\hline Yes & $100.00(50 / 50)$ & $100.00(28 / 28)$ & 0.00 & UNDF & UNDF \\
\hline
\end{tabular}




\section{Continued}

\begin{tabular}{|c|c|c|c|c|c|}
\hline $\begin{array}{l}\text { Maternal nutrition and physical activity } \\
\text { characteristics }\end{array}$ & Controls \% & Cases \% & OR & {$[95 \% \mathrm{CI}]$} & $P$-value \\
\hline \multicolumn{6}{|l|}{ Alcohol consumption during pregnancy } \\
\hline No & $100.00(50 / 50)$ & $100.00(28 / 28)$ & & 1.00 (Ref) & \\
\hline Yes & $0.00(0 / 50)$ & $0.00(0 / 28)$ & 0.00 & UNDF & UNDF \\
\hline \multicolumn{6}{|l|}{ Cigarets consumption during pregnancy } \\
\hline No & $100.00(50 / 50)$ & $100.00(28 / 28)$ & & 1.00 (Ref) & \\
\hline Yes & $0.00(0 / 50)$ & $0.00(0 / 28)$ & 0.00 & UNDF & UNDF \\
\hline \multicolumn{6}{|c|}{ Passive cigarets consumption during pregnancy } \\
\hline No & $68.00(34 / 50)$ & $57.14(16 / 28)$ & & 1.00 (Ref) & \\
\hline Yes & $32.00(16 / 50)$ & $42.86(12 / 28)$ & 1.59 & $0.61-4.14$ & 0.33 \\
\hline \multicolumn{6}{|l|}{ Physical activity } \\
\hline No & $62.00(31 / 50)$ & $78.57(22 / 28)$ & & 1.00 (Ref) & \\
\hline Yes & $38.00(19 / 50)$ & $21.43(6 / 28)$ & 0.44 & $0.15-1.29$ & 0.13 \\
\hline \multicolumn{6}{|l|}{ Infant characteristics } \\
\hline Weightbirth [Mean \pm s.d] (g) & $3076.00 \pm 533.97$ & $4310.71 \pm 246.96$ & & & 0.00 \\
\hline \multicolumn{6}{|l|}{ Gestational age (weeks) } \\
\hline$<38$ & $16.00(8 / 50)$ & $7.14(2 / 28)$ & 0.40 & $0.07-2.05$ & 0.26 \\
\hline$[38-40]$ & $74.00(37 / 50)$ & $67.85(19 / 28)$ & 0.74 & $0.26-2.04$ & 0.56 \\
\hline$>40$ & $10.00(5 / 50)$ & $25.00(7 / 28)$ & 3.00 & $0.85-10.56$ & 0.07 \\
\hline
\end{tabular}

Abbreviations: Percentage \% in (n/Total); OR, Odds ratio; CI, Confidence interval; UNDF, Undefined; Ref, Reference category.

However, the other sociodemographic factors were not associated with macrosomia. In addition, pre-pregnancy overweight (OR: 3.28, 95\% CI: 1.23 - 8.70), pre-pregnancy pooled overweight and obesity (OR: 5.31, 95\% CI: $1.92-14.62$ ), self-reported history of macrosomia (OR: $8.00,95 \%$ CI: 1.53 - 41.78), and self-reported history of overweight/obesity (OR: 10.13, 95\% CI: 2.52 - 40.77) were significantly found to be predisposing factors for macrosomia. Neonate's gestational age over 40 weeks approached also the statistical significance (OR: 3.00, 95\% CI: 0.94 - 10.56). When adjusting for confounding factors (Table 3), the multivariate logistic regression model indicated that obesity and overweight history (aOR: 7.49, 95\% CI: $1.52-41.41, p$-value $=0.01$ ), pre-pregnancy pooled overweight and obesity (aOR: 5.24, 95\% CI: $1.54-17.82$, $p$-value $=0.00$ ), and hormone therapy (aOR: $18.23,95 \% \mathrm{CI}: 1.54-214.51, p$-value $=0.02$ ) were significantly associated with increased odds for macrosomia condition.

\section{Discussion}

Previous research have been carried out to identify the association between high birth weight and diabetes mellitus, however, the majority of macrosomic neonates are born to healthy pregnant women. Furthermore, less attention has 
Table 3. Independent risk factors for macrosomia by logistic regression analysis.

\begin{tabular}{lccc}
\hline & Adjusted odd ratio & {$[95 \% \mathrm{CI}]$} & $P$-value \\
\hline Confounding factors & 3.93 & $0.56-27.63$ & 0.16 \\
Maternal age (>40 years) & 7.94 & $1.52-41.41$ & 0.01 \\
Obesity and overweight history & 3.59 & $0.48-26.60$ & 0.20 \\
Macrosomia history & 5.24 & $1.54-17.82$ & 0.00 \\
Pooled pre-pregnancy BMI $\left(\geq 25 \mathrm{~kg} / \mathrm{m}^{2}\right)$ & 18.23 & $1.54-214.51$ & 0.02 \\
Hormone therapy & &
\end{tabular}

been paid to the associated risk factors of fetal macrosomia restricted to non-diabetic and healthy mothers. The present study is the first to ascertain the prevalence of macrosomia condition and its associated predictors in Tiznit Province and Souss-Massa Region, Morocco. Our findings showed that the prevalence rate is higher than both the national and the African rates. For instance, in African countries, macrosomia prevalence of $7.4 \%, 10.5 \%$, and $14.9 \%$, were proclaimed in Ghana, Nigeria, and Algeria, respectively [9] [20] [21].

Nevertheless, the prevalence rate assessed in Tiznit (35.89\%) was more or less expected by reason of the general increasing tendency of macrosomia in many parts of the world, and mostly owing to the complex and multifactorial aetiology of macrosomia, in addition to the cultural, socio-demographic and nutritional transition Morocco is currently undergoing [22].

\subsection{Macrosomia Risk Factors}

Macrosomia is a complex and multifactorial condition that may have genetic and environmental causes. The precise mechanism of high birth weight is unknown. Fetal genetic factors involve the genetic composition or inherent growth potential of individuals, genetic syndromes like Beckwith-Wiedemann pathology, and male sex, whereas maternal genetic factors could encompass history of macrosomia, maternal height, obesity and diabetes [23]. More recently, genetic expression of the paternal insulin-like growth factor 2 (IGF2) was found to be associated with fetal birth weight [24]. Even though, BMI was revealed to be from $40 \%$ to $70 \%$ heritable, less than $2 \%$ of the obesity-susceptible genetic loci have been identified [25] and have been demonstrated to have small effects on BMI. Moreover, obesity risk component could have little role in the recent tendency of birth weight distribution, most likely because genetic changes would require generations to be maintained, and to affect birth weight [26]. Constitutional or genetic-based macrosomia differs from environmental-based macrosomia and is defined as the infant growth beyond its genetic potential [27]. Environmental and lifestyle determinants are also marked by an increased fat accumulation during fetal life and could play bigger roles in the rapid and high incidence of macrosomia [28]. They include both non-modifiable factors such as: infant gender, gestational age, and parity, as well as modifiable factors like: 
GWG, pre-gestational weight and BMI, lifestyle behaviors (i.e.: diet, smoking and alcohol consumption, as well as physical activity) [26].

The prenatal and in utero growth is dependent upon maternal nutritional status, and growing evidence has demonstrated that the latter is often correlated with GWG and pre-pregnancy BMI [29]. According to Moroccan Ministry of Health recommendations, GWG should never be less than $7 \mathrm{~kg}$ in obese or overweight women [30]. In this study, the GWG was estimated to $7.80 \pm 2.12 \mathrm{~kg}$ among Tiznit parturients. However the mean GWG between geographic localities was assessed to 7.28 and $6.75 \mathrm{~kg}$ in urban and rural areas, respectively. The slightly elevated GWG in urban zone might be a consequence of the discrepancy of living conditions (i.e.: reduced physical activity and active commuting to work, changes in lifestyle, urbanization, and sedentary employment that creates obesogenic environment) [9]. As reported in a recent study [31], there is a positive correlation between macrosomia and maternal GWG (Pearson's coefficient $r=0.33$ and $p$-value $=0.00$, result not shown). Unfortunately, it was impossible to calculate the relative odds ratio due to the absence of control individuals with excessive GWG. Significant associations between high birth weight and pre-pregnancy BMI were observed in overweight and in pooled obese/overweight mothers (unadjusted OR: 3.28 , 95\% CI: 1.23 - 8.70, and unadjusted OR: 5.31, 95\% CI: 1.92 - 14.62, respectively. Such correlations have also been noted in an Asian population [32]. The mechanism by which pre-pregnancy $\mathrm{BMI}$ is linked to GWG via maternal nutrition during pregnancy is being debated and unsolved [33].

Nearly one third of the non-diabetic women has delivered by means of caesarean section, to which macrosomia was linked with eleven higher risk (OR: 11.05, 95\% CI: 3.63 - 33.60, $p$-value $=0.00)$. Similar rate of caesarean section was recorded in North Africa and Southern Europe regions influenced together by the Mediterranean culture [34]. Additionally, caesarean delivery was four times more likely in pregnant obese women with a pre-gravid BMI $\geq 30 \mathrm{~kg} / \mathrm{m}^{2}$ (OR: 4.16, 95\% CI: $0.98-19.09, p$-value $=0.05$, result not shown). As caesarean section factor constitutes a consequence of macrosomia and not an eventual cause, it was retrieved from logistic regression analysis as a confounding factor.

Oxytocin and progestogens (progesterone, estrogen, utrogestan and corticoids) are among drugs administered to pregnant women in Tiznit hospital to facilitate their childbirths. Recent studies have proven the role of progestogens in maintaining pregnancy and preventing against miscarriages [35]. Moreover, vaginal progesterone was not found to be associated with a reduction of the risk of preterm delivery [36], contrary to corticosteroids [37]. It has been recently confirmed that progestogen exposure might negatively influence reproductive health, in terms of fertility and sexual differentiation [38]. Additionally, it is acknowledged that the uterus and mammal glands are negatively affected by the estrogens used in hormone therapy [39]. Through the present study, hormone administration to pregnant women was for the first time assessed and signifi- 
cantly associated with 18 times high risk of macrosomia (OR: 18.23, 95\% CI: $1.54-214.9, p$-value $=0.02$ ). To my knowledge, no study has yet explored the effect of hormone therapy on high birth weight, which makes any comparison difficult.

\subsection{Cultural, Socio-Demographic and Nutritional Factors}

The Province of Tiznit belongs to the Souss-Massa valley in Southern Morocco and covers a surface of $5173 \mathrm{~km}^{2}$. Geographically, Tiznit area is limited to the North by Taroudant and Chtouka Ait Baha Provinces, to the South by Sidi Ifni and Tata Provinces, to the East by Tata and Taroudant, and to the West by the Atlantic Ocean [40]. Tiznit is also an arid area that is characterized by high rates of poverty and illiteracy, mainly in rural zones.

Demographically, it has a total population of 207,000 , with 81,000 urban inhabitants and 126,000 rural inhabitants [41]. The population is made up different ethnic origins and groups: the Amazighs or Berbers that represent the majority, the Arabs, the Jews, and the sub-Saharans and Africans.

Generally, high socio-economic status (education level, income, ethnicity and residence) has a positive impact on health condition. Also, educated people are more aware of health inputs, and tend to effectively and continuously adopt their healthy behaviors [42]. The latter depend more directly on having financial resources to purchase health [43]. The present study failed to demonstrate a significant correlation between macrosomia and socio-demographic/economic status (SES), except for maternal education level greater than 12 years, where no macrosomic neonate was among the cases $(p$-value $=0.01)$. However, recent evidence has revealed contradictory and conflicting results. While it was reported no association between SES and high birth weight [44], multivariate analysis models demonstrated that high SES increases positively health outcomes by reducing high birth weight risk [45].

Nutritional data during pregnancy were also collected, and the analysis showed no significant differences between the consumption of individual group of products by mothers and fetal macrosomia. This is most likely due to the benefits of the Mediterranean diet generally adopted in Morocco. Obviously, it has scientifically been approved that Mediterranean nutrition is healthy, balanced, and consequently, recognized as a food model [46]. Moreover, the Arab/ Amazigh cuisine does not make exception to that rule as it is based on vegetables, fruits, cereals, fish/seafood, beef/goat/chicken meats, dairy products, virgin olive oil...etc. Besides, the Souss-Massa valley is characterized by many local products such as: almonds (Prunus dulci), cactus of barbary (Opuntia ficus-indica), capers (Capparis spinosa), as well as by aromatic and medicinal plants like: mint (Mentha peperita), rosemary (Rosemarinus officinalis), lavender (Lavendula dentata), carob (Ceratonia siliqua), thymus (Artemesiaherba-alba), henna (Lawsonia inermis), and aloe (Aloe vera) [47].

Not to mention that Tiznit Province is situated in the Arganeraie Biosphere 
Reserve inscribed in 2014 at the United Nations International Educational, Scientific and Cultural Organization (UNESCO) [48] list of the intangible cultural heritage of humanity. Argan oil is then traditionally extracted from argan trees (Argania spinosa), an endemic woodland species to Morocco, and is frequently used in human and animal diet. In Morocco, several studies have examined the nutritional, medical, cosmetic, therapeutic, and pharmacologic qualities of argan oil. For example, Amazigh medicine is based on daily use and consumption of both argan and olive oils to prevent cardiovascular pathologies, to treat teenage acne, and rheumatism-induced pain [49]. This is principally due to their high amounts of mono- and poly-unsaturated fat acids, sterols, tocopherols, and poly-phenols [50]. Scientific evidence is additionally mounting for the role of argan oil in the prevention of prostate cancer [51], of diabetes mellitus [52], as well as in blood triglycerids, Low Density Lipoprotein cholesterol, E vitamin and lipoperoxids reduction [53]. Other works have contributed to enhance the knowledge on argan oil's anti-hypertensive, anti-inflammatory, anti-oxydant, anti-microbe, lipolytic and analgesic proprieties [54], in conjunction with its beneficial effect on obesity risk prevention [55]. Finally, it was reported short while ago that argan oil-enhanced nutrition can be advocated in post-menopausal syndromes [56].

Along with the dietary patterns cited above, physical activities mainly, field work, walking, gardening, domestic chores, and trainings constitute the other maternal lifestyle factor that might reduce the risk of neonate macrosomia in the present study (OR: 0.44 and 95\% CI: 0.15 - 1.29). A recent research has shown that colder climate in Northern country was linked with less physical activity and more energy-rich diets, which might increase body weight in Chinese pregnant women [32], the opposite explanation would be true for arid climates like the one in Tiznit. The pre-pregnancy BMI statistics could confirm that, as more than $53 \%(42 / 78)$ of women had normal/underweight nutritional status, whose $35 \%$ (27/78) are resident in remote areas of Tiznit Province. Consequently, both lifestyle factors should be considered as protective factors against high birth weight in Tiznit Province.

\section{Conclusion}

The present research was designed to contribute in neonate macrosomia prevention by identifying its risk factors in non-diabetic mothers. The findings showed that pre-pregnancy BMI $\geq 25 \mathrm{~kg} / \mathrm{m}^{2}$, overweight/obesity history, and hormone therapy should be considered as independent risk factors for macrosomic infants with birth weight $\geq 4000 \mathrm{~g}$. Pre-gravid BMI and GWG are two crucial predictors associated with maternal and fetal outcomes that should be routinely implemented by health professional performing prenatal care. The two factors need more attention, must be estimated and controlled, specifically for high-risk women (i.e.: with pre-existing obesity or overweight histories). Potential parents should be sensitized about macrosomia prevention, and mothers have to be en- 
couraged to decrease their perinatal weight by surveilling their lifestyle behaviors. Such interventions are believed to reduce the risk of delivering macrosomic neonates, and to have positive impact on pregnancy outcomes. This pilot study has some limitations and could be developed further by (i) extending its duration and including newborn's gender, (ii) recruiting more patients from other hospitals, and therefore allowing for more differences between areas, and by (iii) implementing blood biomarkers like pregnancy-associated plasma protein A (PAPP-A) and $\beta$-human chorionic gonadotropin ( $\beta$-hCG). Furthermore, much more work is needed to investigate in details the intrauterine exposure to hormone therapy before any conclusion can be drawn or adopted.

\section{Author's Contributions}

Amal Korrida: Project development and design, data analysis, and manuscript writing.

\section{Acknowledgements}

The author would like to thank all the participants and their infants who kindly accepted to be part of the present research. I am deeply grateful to Mr. Azouz Elhasnaoui the director of Tiznit ISPITS and to Dr. Lamia Chakiri, the former Moroccan Ministry of Health Delegate to the Province of Tiznit, for facilitating the study and for their kindness. The author acknowledges the assistance of the undergraduate students Khadija Bella and Khadija Warghad during the data collection, as well as the unconditional help of the medical, paramedical staff and midwives in charge at the maternity of Tiznit Hassan I CHP.

\section{References}

[1] Jolly, M.C., Sebire, N.J., Harris, J.P., Regan, L. and Robinson, S. (2003) Risk Factors for Macrosomia and Its Clinical Consequences: A Study of 350,311 Pregnancies. European Journal of Obstetrics \& Gynecology and Reproductive Biology, 11, 9-14. https://doi.org/10.1016/S0301-2115(03)00154-4

[2] Jeffers, E.C. (2016) Macrosomic Infants Born to Non-Diabetic Mothers in Nova Scotia: Determinants and Development of a Risk Prediction Model. Ph.D. Thesis, Dalhousie University Halifax, Nova Scotia.

[3] Amini, P., Maroufizadeh, S., Hamidi, O., Samani, R.O. and Sepidarkish, M. (2016) Factors Associated with Macrosomia among Singleton Live-Birth: A Comparison between Logistic Regression, Random Forest and Artificial Neural Network Methods. Epidemiology, Biostatistics and Public Health, 13, e119851-e119859.

[4] Barker, D.J., Eriksson, J.G., Forsen, T. and Osmond, C. (2002) Fetal Origins of Adult Disease: Strength of Effects and Biological Basis. International Journal of Epidemiology, 31, 1235-1239. https://doi.org/10.1093/ije/31.6.1235

[5] Schwartz, N., Quant, H.S., Sammel, M.D. and Parry, S. (2014) Macrosomia Has Its Roots in Early Placental Development. Placenta, 35, 684-690. https://doi.org/10.1016/j.placenta.2014.06.373

[6] Usta, A., Usta, C.S., Yildiz, A., Ozcaglayan, R., Dalkiran, E.S., Savkli, A. and Taskiran, M. (2017) Frequency of Fetal Macrosomia and the Associated Risk Factors in 
Pregnancies without Gestational Diabetes Mellitus. The Pan African Medical Journal, 26, 1-8. https://doi.org/10.11604/pamj.2017.26.62.11440

[7] Lepercq, J., Timsit, J. and Hauguel-de Mouzon, S. (2000) Ethiopathogénie de la macrosomiefotale. Journal de Gynécologie Obstétrique et Biologie de la Reproduction, 29, 6-12.

[8] Islam, R. (2012) Prevalence and Predictors of Macrosomia Newborn: Northern Norwegian Mother-and-Child Study. Ph.D. Thesis, University of Tromsq, Tromsø.

[9] Abubakari, A., Kynast-Wolf, G. and Jahn, A. (2015) Prevalence of Abnormal Birth Weight and Related Factors in Northern Region, Ghana. BMC Pregnancy and Childbirth, 15, 1-8. https://doi.org/10.1186/s12884-015-0790-y

[10] Van Wootten, W. and Turner, R.E. (1999) The Prevalence of Macrosomia in Neonates of Gestational Diabetic Mothers: Analysis of Risk Factors. Journal of the American Dietetic Association, 99, A32. https://doi.org/10.1016/S0002-8223(99)00502-7

[11] Gyselaers, W. and Martens, G. (2012) Increasing Prevalence of Macrosomia in Flanders, Belgium: An Indicator of Population Health and a Burden for the Future. Facts, Views \& Visions in ObGyn, 4, 141-143.

[12] Rodrigues, S. (1999) Epidemiology of Gestational Diabetes Mellitus and Infant Macrosomia among the Cree James Bay. Ph.D. Thesis, School of Dietetics and Human Nutrition, McGill University, Montreal.

[13] Fettah, M. (2016) La macrosomie fotale à terme (à propos de $340 \mathrm{cas}$ ). Ph.D. Thesis, Université Sidi Mohammed Ben Abdellah, Faculté de Médecine et de Pharmacie, Fès.

[14] EL Bakkali, M. and Azzouzi, Y. (2014) Les facteurs associés à la survenue de la macrosomie chez le nouveau-né à l'hôpital régional Cherif Idrissi dans la Région du Gharb, Maroc. European Scientific Journal, 10, 11-22.

[15] Li, Y., Liu, Q.F., Zhang, D., Shen, Y., Ye, K., Lai, H.L., Wang, H.Q., Hu, C.L., Zhao, Q.H. and Li., L. (2015) Weight Gain in Pregnancy, Maternal Age and Gestational Age in Relation to Fetal Macrosomia. Clinical Nutrition Research, 4, 104-109. https://doi.org/10.7762/cnr.2015.4.2.104

[16] Pates, J.A., McIntire, D.D., Casey, B.M. and Leveno, K.J. (2008) Predicting Macrosomia. Journal of Ultrasound in Medicine, 27, 39-43. https://doi.org/10.7863/jum.2008.27.1.39

[17] WHO (World Health Organization) (1995) Physical Status: The Use and Interpretation of Anthropometry. Report of a WHO Expert Committee, WHO Technical Report Series 854, World Health Organization, Geneva.

[18] IOM (Institute of Medicine) and NRC (National Research Council) (2009) Weight Gain during Pregnancy: Reexamining the Guidelines. The National Academies Press, Washington DC.

[19] Stotland, N.E., Hopkin, L.M. and Caughey, A.B. (2004) Gestational Weight Gain, Macrosomia, and Risk of Cesarean Birth in Non-Diabetic Nulliparas. The American College of Obstetricians and Gynecologists, 104, 671-677.

[20] Onyearugha, C.N. and Ugboma, H.A.A. (2014) Macrosomia: Prevalence and Predisposing Factors as Seen at a University Teaching Hospital, South-South Nigeria. Journal of Medical Investigations and Practice, 9, 12-15.

[21] Koyanagi, A., Zhang, J., Dagvadorj, A., Hirayama, F., Shibuya, K. and Gülmezoglu, A.M. (2013) Macrosomia in 23 Developing Countries: An Analysis of a Multicountry, Facility Based, Cross-Sectional Survey. The Lancet, 381, 476-483. 
https://doi.org/10.1016/S0140-6736(12)61605-5

[22] Benjelloun, S. (2002) Nutrition Transition in Morocco. Public Health Nutrition, 5, 135-140. https://doi.org/10.1079/PHN2001285

[23] Beckmann, C.R.B., Ling, F.W., Herbert, W.N.P., Laube, D.W., Smith, R.P., Casanova, R., Chuang, A., Goepfert, A.R., Hueppchen, N.A. and Weiss, P.M. (2014) Obstetrics and Gynecology. 7th Edition, Wolters Kluwer Health.

[24] Demetriou, C., Abu-Amero, S., Thomas, A.C., Ishida, M., Aggarwal, R., Al-Olabi, L., Leon, L.J., Stafford, J.L., Syngelaki, A., Peebles, D., Nicolaides, K.H., Regan, L., Stanier, P. and Moore, G.E. (2014) Paternally Expressed, Imprinted Insulin-Like Growth Factor-2 in Chorionic Villi Correlates Significantly with Birth Weight. PLoS ONE, 9, e85454. https://doi.org/10.1371/journal.pone.0085454

[25] Loos, R.J. (2009) Recent Progress in the Genetics of Common Obesity. British Journal of Clinical Pharmacology, 68, 811-829. https://doi.org/10.1111/j.1365-2125.2009.03523.x

[26] Voldner, N. (2009) Modifiable Determinants of Newborn Macrosomia and Birth Complications. STORK-Study. Oslo University Hospital, Rikshospitalet Faculty of Medicine.

[27] Hod, M. and Pardo, J. (2009) Environmental Rather than Genetic Fetal Overgrowth: Defining the Difference and Hints for Diagnosis and Management. Ultrasound in Obstetrics \& Gynecology, 33, 375-378. https://doi.org/10.1002/uog.6352

[28] Kabali, B.C. and Werler, M.M. (2007) Pre-Pregnancy Body Mass Index, Weight Gain and the Risk of Delivering Large Babies among Non-Diabetic Mothers. International Journal of Gynecology \& Obstetrics, 97, 100-104. https://doi.org/10.1016/j.ijgo.2007.02.001

[29] Xie, Y.J., Peng, R., Han, L., Zhou, X., Xiong, Z., Zhang, Y., Li, J., Yao, R., Li, T. and Zhao, Y. (2016) Associations of Neonatal High Birth Weight with Maternal Pre-Pregnancy Body Mass Index and Gestational Weight Gain: A Case-Control Study in Women from Chongqing, China. BMJ Open, 6, e010935.

https://doi.org/10.1136/bmjopen-2015-010935

[30] Guide Marocain de Nutrition (Ministère de la Santé 2016) A l'usage des professionnels de santé.

[31] Redfern, K.M., Rees, G.A. and Pinkney, J.H. (2016) Maternal Lifestyle Factors and Fetal Macrosomia Risk: A Review. EMJ Reproductive Health, 2, 52-58.

[32] Xiao, L., Ding, G., Vinturache, A., Xu, J., Ding, Y., Guo, J., Huang, L., Yin, X., Qiao, J., Thureraja, I. and Ben, X. (2017) Associations of Maternal Prepregnancy Body Mass Index and Gestational Weight Gain with Birth Outcomes in Shanghai, China. Nature Scientific Reports, 7, 1-8.

[33] Shin, D., Lee, K.W. and Song, W.O. (2016) Pre-Pregnancy Weight Status Is Associated with Diet Quality and Nutritional Biomarkers during Pregnancy. Nutrients, 8, 1-12. https://doi.org/10.3390/nu8030162

[34] Betrán, A.P., Ye, J., Moller, A.B., Zhang, J., Gülmezoglu, A.M. and Torloni, M.R. (2016) The Increasing Trend in Caesarean Section Rates: Global, Regional and $\mathrm{Na}$ tional Estimates: 1990-2014. PLoS ONE, 11, e0148343. https://doi.org/10.1371/journal.pone.0148343

[35] Haas, D.M. and Ramsey, P.S. (2013) Progestogen for Preventing Miscarriage. The Cochrane Database of Systematic Reviews, 10, 1-53. https://doi.org/10.1002/14651858.CD003511.pub3

[36] Azria, E. (2016) The Use of Progestatives for the Prevention of Spontaneous Pre- 
term Birth. Journal de Gynécologie Obstétrique et Biologie de la Reproduction, 45, 1280-1298. https://doi.org/10.1016/j.jgyn.2016.09.012

[37] Schmitz, T. (2016) Prevention of Preterm Birth Complications by Antenatal Corticosteroid Administration. Journal de Gynécologie Obstétrique et Biologie de la Reproduction, 45, 1399-1417. https://doi.org/10.1016/j.jgyn.2016.09.008

[38] Jefferson, W.N. and Williams, C.J. (2011) Circulating Levels of Genistein in the Neonate, Apart from Dose and Route, Predict Future Adverse Female Reproductive Outcomes. Reproductive Toxicology, 31, 272-279. https://doi.org/10.1016/j.reprotox.2010.10.001

[39] Rimoldi, G., Christoffel, J., Seidlova-Wuttke, D., Jarry, H. and Wuttke, W. (2007) Effects of Chronic Genistein Treatment in Mammary Gland, Uterus, and Vagina. Environmental Health Perspectives, 115, 62-68. https://doi.org/10.1289/ehp.9367

[40] Ministère de l'Equipement, du Transport, de la Logistique et de l'Eau (2017) La monographie de la Province de Tiznit.

http://www.equipement.gov.ma/Carte-Region/RegionAgadir/Presentation-de-la-reg ion/Monographie/Pages/Monographie-Tiznit.aspx

[41] Haut-Commissariat au Plan, Recensement général de la population et de l'habitat au Maroc (2014). http://www.hcp.ma/downloads/RGPH-2014_t17441.html

[42] Grossman, M. (2005) Education and Non-Market Outcomes. National Bureau of Economic Research Working Paper No. 11582.

[43] Pampel, F.C., Patrick, M., Krueger, P.M. and Denney, J.T. (2010) Socioeconomic Disparities in Health Behaviors. Annual Review of Sociology, 36, 349-370. https://doi.org/10.1146/annurev.soc.012809.102529

[44] Cesur, R. and Kelly, I.R. (2010) From Cradle to Classroom: High Birth Weight and Cognitive Outcomes. In: Forum for Health Economics \& Policy, Walter de Gruyter GmbH \& Co. KG, Berlin, Boston, 13.

[45] Webb, R. (2014) High Birth Weight and Socio-Economic Status. University of Canterbury, Oxford University Press, New York.

[46] Altomare, R., Cacciabaudo, F., Damiano, G., Palumbo, V.D., Gioviale, M.C., Bellavia, M., Tomasello, G. and Lo Monte, A.I. (2013) The Mediterranean Diet: A History of Health. Iranian Journal of Public Health, 42, 449-457.

[47] Ministère de l'Agriculture et de la Pêche Maritime. Direction de Développement des Filières de Production. Produits du terroir du Maroc (2011) Catalogue National Edition. http://www.agriculture.gov.ma/sites/default/files/Produits-du-terroir.pdf

[48] UNESCO (United Nations International Educational, Scientific and Cultural Organization) (2014) Argan, Practices and Know-How Concerning the Argan Tree. https://ich.unesco.org/en/RL/argan-practices-and-know-how-concerning-the-argan $\underline{\text {-tree-00955 }}$

[49] Charrouf, Z. and Guillaume, D. (1999) Ethnoeconomical, Ethnomedical, and Phytochemical Study of Arganiaspinosa (L.) Skeels. Journal of Ethnopharmacology, 67, 7-14. https://doi.org/10.1016/S0378-8741(98)00228-1

[50] Khallouki, F., Younos, C., Soulimani, R., Oster, T., Charrouf, Z., Spiegelhalder, B., Bartsch, H. and Owen, R.W. (2003) Consumption of Argan Oil (Morocco) with Its Unique Profile of Fatty Acids, Tocopherols, Squalene, Sterols and Phenolic Compounds Should Confer Valuable Cancer Chemo-Preventive Effects. European Journal of Cancer Prevention, 12, 67-75.

https://doi.org/10.1097/00008469-200302000-00011

[51] Bennani, H., Drissi, A., Giton, F., Kheuang, L., Fiet, J. and Adlouni, A. (2007) Anti- 
proliferative Effect of Polyphenols and Sterols of Virgin Argan Oil on Human Prostate Cancer Cell Lines. Cancer Detection and Prevention, 31, 64-69.

https://doi.org/10.1016/j.cdp.2006.09.006

[52] Ould Mohamedou, M.M., Zouirech, K., El Messal, M., El Kebbaj, M.S., Chraibi, A. and Adlouni, A. (2011) Argan Oil Exerts an Antiatherogenic Effect by Improving Lipids and Susceptibility of LDL to Oxidation in Type 2 Diabetes Patients. International Journal of Endocrinology, 2011, Article ID: 747835.

[53] Cherki, M., Derouiche, A., Drissi, A., El Messal, M., Bamou, Y., Idrissi-Ouadghiri, A., Khalil, A. and Adlouni, A. (2005) Consumption of Argan Oil May Have an Antiatherogenic Effect by Improving Paraoxonase Activities and Antioxidant Status: Intervention Study in Healthy Men. Nutrition, Metabolism and Cardiovascular Diseases, 15, 352-360. https://doi.org/10.1016/j.numecd.2004.08.005

[54] El Kebbaj, R. (2012) Base moléculaire des effets de l'huile d'argan sur le métabolisme mitochondrial et peroxysomal des acides gras et sur l'inflammation. $\mathrm{PhD}$ Thesis, Sciences Agricoles, Université de Bourgogne.

[55] Adlouni, A., Christon, R., Cherki, M., Khalil, A. and ElMessal, M. (2008) The Nutritional Benefits of Argan Oil in Obesity Risk Prevention. Atheroscerosis, 9, 137-138.

[56] El Monfalouti, H., Charrouf, Z., El Hamdouchi, A., Labraimi, H., Chafchaouni-Moussaoui, I., Kartah, B., El Kari, K., Bensouda, Y., Derouich, A., Dodin, S., Denhez, C., Guillaume, D. and Agnaou, H. (2013) Argan Oil and Postmenopausal Moroccan Women: Impact on the Vitamin E Profile. Natural Product Communications, 8, 55-63. 